\title{
Femoral head ostectomy following osteotomy of the greater trochanter in a pony with chronic coxofemoral luxation
}

\author{
Robin van den Boom', Astrid B. M. Rijkenhuizen und Biörn P. Meii \\ Department of Equine Sciences, Section Orthopedic Surgery², Department of Clinical Sciences of Companion Animals ${ }^{1}$, Faculty of Veterinary Medicine, Utrecht
}

\begin{abstract}
Summary
This report describes coxofemoral luxation in a mini-Shetland mare treated by femoral head resection following osteotomy of the greater trochanter. This technique provides excellent exposure of the coxofemoral joint and reattachment of the trochanter did not lead to complications. The pony made a good recovery and was able to walk and trot at pasture. Femoral head resection is a realistic treatment option to resolve lameness in small horse breeds with chronic coxofemoral luxation. Early surgical intervention is advocated to prevent extended periods of non-weightbearing lameness which may lead to complications in the contralateral limb.
\end{abstract}

Key words: coxofemoral, luxation, resection, osteotomy, greater trochanter, pony

Femurkopfresektion nach Osteotomie des großen Trochanter bei einem Pony mit chronischer Hüftgelenksluxation

In diesem Artikel wird eine Luxation des Coxofemoralgelenks bei einer Mini-Shetland Stute vorgestellt, welche mit der Resektion des Femurkopfes nach Zugang via Osteotomie des Trochanter Major behandelt wurde. Diese Technik erlaubt eine ausgezeichnete Übersicht über das Coxofemoralgelenk, und die Wiederbefestigung des Trochanter ergab keine Komplikationen. Das Pony erholte sich gut von der Operation und kann sich problemlos im Schritt und Trab auf der Weide fortgewegen. Die Resektion des Femurkopfes stellt eine mögliche Therapie dar, um eine chronische Lahmheit nach Luxation des Hüftgelenks bei kleinen Pferden und Ponies zu behandeln. Frühes chirurgisches Eingreifen ist wichtig um eine chronische ernsthafte Lahmheit zu verhindern, die zu Komplikationen an der kontralateralen Gliedmaße führen kann.

Schlüsselwörter: Hüftgelenk, Luxation, Resektion, Osteotomie, Trochanter major, Pony

\section{Introduction}

Coxofemoral luxation is a rare cause of lameness in horses and ponies, although small breeds appear to be affected more often than horses (Stashak 1987, Malark et al.1992, Clegg and Butson.1996). Conservative treatment generally does not lead to satisfactory results, whereas varying degrees of success have been achieved using surgical procedures (Platt et al.1990, Garcia-Lopez et al.2001). Successful femoral head resection via a cranial approach has been described in cattle and horses (Platt et al.1990) and Squire et al. (1991) described femoral head resection following greater trochanter osteotomy in experimental animals but not in patients. This report describes a coxofemoral luxation in a mini-shetland pony which was treated by femoral head resection, following osteotomy of the greater trochanter.

\section{Case history}

A two-year old mini-Shetland pony mare, weighing $67 \mathrm{~kg}$, was referred with a history of habitual upward fixation of the patella. Initially the pony was found in its stable, unable to bear weight on the right hind limb. The attending veterinarian diagnosed upward fixation of the patella and performed a medial patellar ligament desmotomy on both hind limbs. However, the pony remained severely lame and 7 weeks later it was referred to the Department of Equine Sciences at Utrecht University.

Clinical examination revealed a non-weightbearing right hind limb lameness and the extremity was held in full extension of the stifle and tarsal joints. The limb was held protracted and exorotated with the hoof resting on the ground just in front of the left hind foot. Flexion of the stifle and tarsal joints was possible in both hind limbs and no patellar fixation was observed. Severe atrophy of the semitendinosus, semimembranosus and femoral biceps muscles was present as well as obvious asymmetry in the pelvic region. The distance between the ischial tuber and the greater trochanter was greater on the right side than on the left. Manipulation of the proximal part of the limb was painful and crepitation could be palpated in the region of the coxofemoral joint. The left leg was held in extension and sometimes even in hyperextension in the tarsus. The left tarsocrural joint was slightly distended and a rupture of the peroneus tertius muscle was diagnosed. 
Based on the clinical examination coxofemoral luxation was suspected which could be confirmed on lateral radiographs of the pelvic area with the standing pony. It was decided to manage the luxation surgically and the pony was treated with vedaprofen (Quadrisol ${ }^{\circledR}, 0.7$ cc po bid) until surgery.

\section{Surgical procedure}

Following premedication with detomidine (Domosedan ${ }^{\circledR}, 10$ $\mu \mathrm{g} / \mathrm{kg}$ iv) general anaesthesia was induced with midazolam (Dormicum ${ }^{\circledR}, 0.27 \mathrm{mg} / \mathrm{kg} 0.75 \mathrm{iv}$ ) and ketamine (Narketan ${ }^{\circledR}$, $2.2 \mathrm{mg} / \mathrm{kg}$ iv) and maintained with isoflurane in oxygen. Additional ventro-dorsal radiographs were taken with the pony under general anaesthesia. Radiographs showed a normal left coxofemoral joint whereas the right coxofemoral joint showed craniodorsal displacement of the femoral head, fragmentation of the acetabular ridge and new bone formation around the acetabulum and femoral neck (Fig. 1). The pony was placed in left lateral recumbency and the right gluteal area was prepared for aseptic surgery. Pancuronium (Pavulon ${ }^{\circledR}, 0.06 \mathrm{mg} / \mathrm{kg}$ iv) was administered to obtain muscle

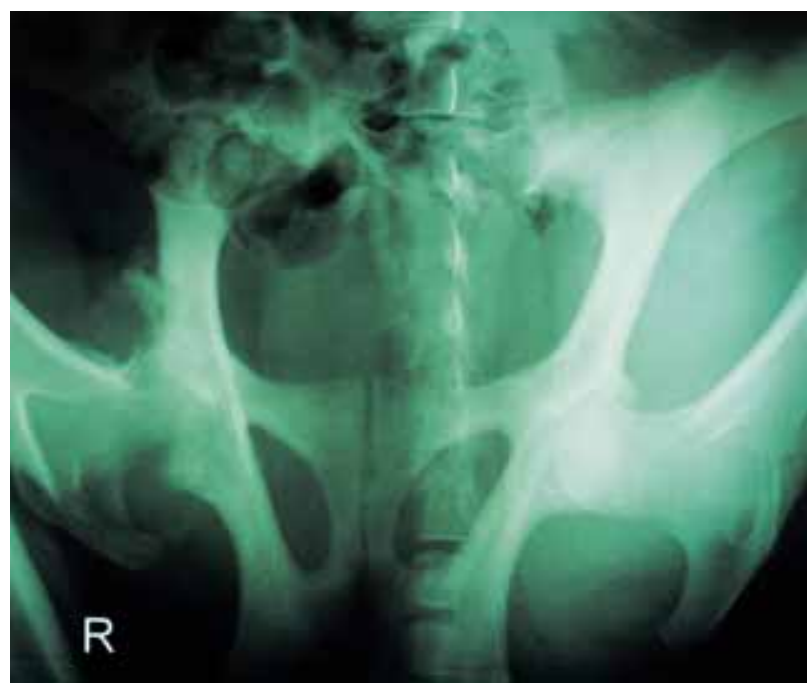

Fig. 1: Ventrodorsal radiograph showing luxation of the right coxofemoral joint and neo-arthrotic changes of the acetabular ridge.

Ventrodorsale Röntgenaufnahme mit Luxation des rechten Hüftgelenks und neoarthrotischen veränderungen des Azetabulumrandes

relaxation. Traction was applied to the right hind limb using an electrical tackle-block to stretch the fibrous and muscular attachments of the coxofemoral joint and facilitate subsequent mobilisation. The skin was incised between the biceps femoris and the superficial gluteal muscles over the greater trochanter. The insertion of the superficial gluteal muscle was separated from the third trochanter. The medial gluteal muscle was dissected from the cranial part of the greater trochanter and an osteotomy was performed of the caudal portion. The accessory and deep gluteal muscles were freed from the greater trochanter and fibrous capsular tissue was cut away, allowing inspection of the acetabulum (Fig. 2). Periosteal new bone formation was removed using rongeurs and the luxated femoral head was exposed. Approximately one third of the femoral head had been eroded, probably due to impingement against the os ilium and the remaining cartila- ge was severely damaged (Fig.3). An attempt was made to reduce the coxofemoral luxation but this proved to be impossible as a result of periosteal bone and fibrous tissue formation and muscle contraction. Bearing in mind the severe damage to the femoral head it was decided to perform a femoral head resection. The vastus lateralis of the quadriceps muscle was separated from the femoral neck and an osteotomy was performed as close as possible to the femoral shaft using an oscillating bone saw. The blade of the saw was angled parallel to the shaft of the femur to prevent leaving a sharp edge on the femoral neck, which could irritate the surrounding soft tissues. Following femoral head resection the cavity was filled with bovine collagen (Novacol Fibrillar ${ }^{\circledR}$, Bioplex Medical, Vaals, The Netherlands) to stop diffuse bleeding. The tendinous attachments of the vastus lateralis, deep gluteal and accessory gluteal muscles were sutured using USP 1 and 2-0 polydiaxone (PDS ${ }^{\circledR}$, Ethicon, Norderstedt, Germany). The caudal part of the greater trochanter was re-attached using two Steinman pins $(2 \mathrm{~mm})$ and orthopedic wire (1.25 $\mathrm{mm}$ ) in a tension band configuration (Fig. 4). The tendinous portion of the superficial gluteal muscle was sutured with USP 1 polyglactin 910 (Vicryl ${ }^{\circledR}$, Ethicon, Norderstedt, Germany).

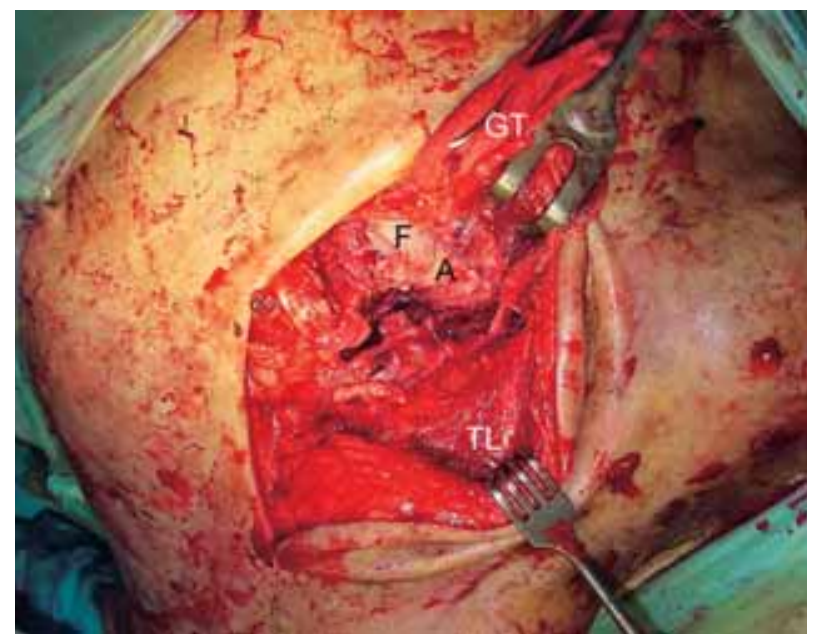

Fig. 2: Intra-operative view of the right coxofemoral joint (cranial to the right, caudal to the left, proximal to the top) following osteotomy of the greater trochanter. GT: retracted greater trochanter with attached the medial and deep gluteal muscles, TL: retracted tensor fasciae latae, A: acetabular ridge and F: femoral head.

Intraoperative Ansicht des rechten Hüftgelenks (kranial rechts, kaudal links, proximal oben) nach Osteotomie des Trochanter major. GT: beiseite gehaltener großer Trochanter mit angeheftetem medialem und tiefem Glutäalmuskel, TL: beiseite gehaltener M. tensor fasciae latae, A: Azetabulumrand, F: Femurkopf

The subcutaneous tissues were apposed using both a continuous and interrupted suture pattern and the skin was closed using an intracutaneous patterns with USP 2-0 polyglecapron (Monocryl ${ }^{\circledR}$, Ethicon, Norderstedt, Germany).

Antibiotics were administered pre-operatively (2 g ampicillin, Ampi 2000 p.i ${ }^{\circledR}$, Aesculaap, Boxtel iv) and were continued post-operatively for two weeks (procain-penicillin, Depocilline ${ }^{\circledR}$, Mycofarm, De Bilt, The Netherlands, $20000 \mathrm{IU} / \mathrm{kg} \mathrm{im}$ for three days, followed by trimethoprim sulfazine, Sultrisan ${ }^{\circledR}$, Anisane, $30 \mathrm{mg} / \mathrm{kg}$ po bid). Vedaprofen was given for another two weeks after the operation. A small amount of serohemorrhagic exsudate leaked from the wound for 3 days but 
it healed by first intention. Weight-bearing gradually improved following surgery over a period of 6 weeks. At 1 week after surgery, the pony was hand-walked for short periods several times a day. On the 10th post-operative day it was noticed that the tip of the left hind hoof was lifted off the ground as a result of flexor tendon laxity. The tendons were not painful and no flexor tendon rupture could be palpated. A Robert-Jones bandage was applied and a shoe with extended branches was fitted. This resulted in a marked improvement and the bandage was removed after two days.

Locomotion continued to improve and after two weeks the pony was given access to a small paddock for several hours a day. By this time a slight exorotation of the right hind limb was present and the pony was able to walk reasonably well. The pony was discharged and the owner was advised to turn it out in a small paddock and to have the pony reshod with extended shoes on the left hind foot after 6 weeks. Follow-up by telephone eight months after surgery revealed that the secondary problems affecting the left hind limb had resolved and that the pony was turned out to pasture during the day. According to the owner the pony was not lame when walking and frequently trots on its own accord.

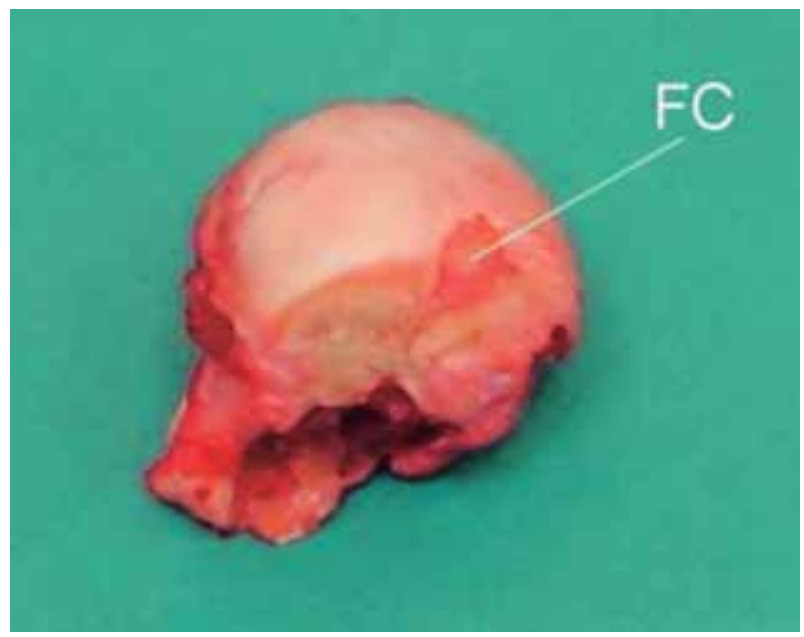

Fig. 3: Close-up view of excised femoral head showing abrasion of cartilage and subchondral bone due to chronic impingement against the ilium.(FC, Fovea capitis)

Resezierter Femurkopf mit Abrasion von Knorpel und subchondralem Knochen durch chronisches Abschleifen am lleum. (FC: Fovea capitis)

\section{Discussion}

Coxofemoral luxation occurs rarely in horses and ponies due to the deep acetabulum and strong fixation of the femoral head by the round and accessory ligaments and the strong surrounding musculature (Nyack et al. 1982, Malark et al. 1992). Trauma (falling or being kicked), violent contraction of the quadriceps muscle while attempting to flex the stifle, or falling on the stifle with the femur in a vertical position are considered to be causes of coxofemoral luxation (Stashak 1987, Squire et al. 1991, Foerner 1992, Malark et al. 1992). Poor hip conformation contributes to coxofemoral luxation in dogs (Hunt and Henry 1985) and has been reported in the horse (Jogi and Norberg 1962, Spiers and Wrigley 1979; Stashak 1987) and could contribute to a less stable coxofemoral joint. Radiographs of the left coxofemoral joint were normal which suggested that poor hip conformation played no role in the coxofemoral luxation on the right side. The femoral head erosion and rapid development of periosteal bone formation are likely to be the result of bone-on-bone movement, rather than being caused by congenital poor hip conformation.

Coxofemoral luxation is frequently seen in combination with upward fixation of the patella (Nyack et al. 1982, Foerner 1992, Malark et al. 1992, Clegg and Butson 1996). Platt et al. (1990) describe a case of upward fixation of the patella secondary to coxofemoral luxation, presumably as a result of the altered position of the limb following luxation (exorotation of stifle and toe and endorotation of the hock) and atrophy of the quadriceps muscle. According to the referring veterinarian the pony in this report suffered frequent episodes of upward patellar fixation prior to coxofemoral luxation which may have contributed to the occurrence of luxation.

Treatment of coxofemoral luxation by repositioning of the femoral head under general anaesthesia, either surgically or non-surgically is rarely successful unless it is performed within a few hours after the inciting incident. Reluxation occurs in the

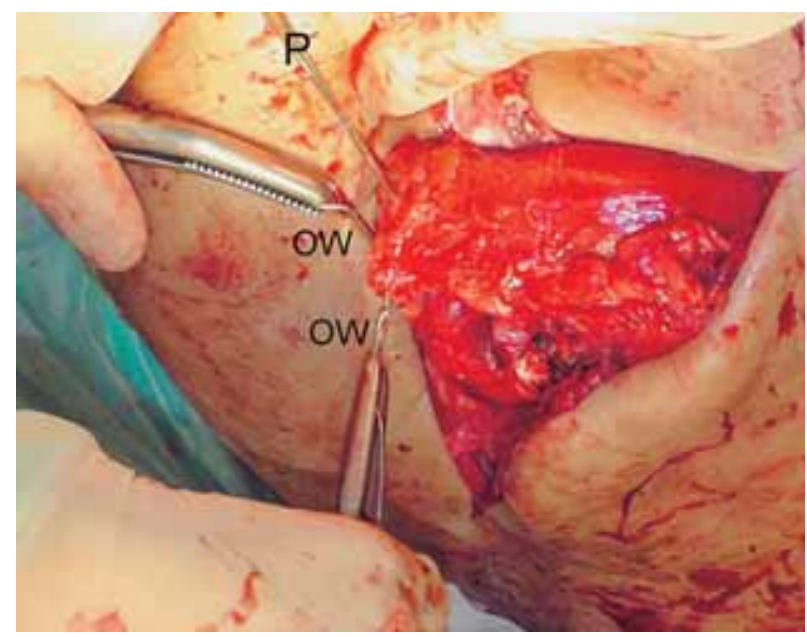

Fig. 4: Intra-operative view of reattachment of the greater trochanter using two Steinman pins $(\mathrm{P})$ and orthopedic wire $(\mathrm{OW})$ (cranial to the right, caudal to the left and proximal to the top). Intraoperative Ansicht der Fixierung des großen Trochanter mittels Steiman-Pin $(P)$ und orthopädischem Draht (OW). (kranial rechts, kaudal links, proximal oben).

majority of cases, especially if there is no attempt at hip joint retention (Stashak 1987, Malark et al. 1992). Successful closed reduction resulted in persistent lameness in one case (Malark et al. 1992) and osteoarthritis in another case (Clegg and Butson 1996) in which reduction was maintained using an Ehmer sling. Reluxation occurs because the round and accessory ligaments rupture at the time of luxation and subsequent filling of the acetabulum with blood clots or granulation tissue. Also in companion animals, where reduction is much more readily maintained by the use of a sling, reluxation occurs frequently and surgical methods of retention are required. Several surgical procedures have been developed for large and small animals to maintain the femoral head within the acetabulum following surgical repositioning (Knowles et al. 1953, Adams 1957, Lawson 1965, Zakiewicz 1967, Hunt and Henry 1985, Lubbe and Verstraete 1990, Malark et al. 1992, Meii et al. 1992). Intra-articular techniques gene- 
rally use a prosthesis for the round ligament or transarticular pins but they damage the articular cartilage and lead to the development of osteoarthritis. Other complications include pin migration and breakage, osteomyelitis and sciatic nerve impairment (Hunt and Henry 1985; Malark et al. 1992; Meii et al. 1992). This has led to the development of methods which provide extra-articular stability through capsulorrhaphy or extracapsular suture techniques, extension of the acetabular rim and the use of pins outside the joint (Meij et al. 1992). After opening of the coxofemoral joint in the pony described in this report it was noted that the acetabulum was severely damaged and too much fibrous tissue and new bone was present to allow repositioning of the femoral head and it was decided to perform a femoral head and neck excision.

In small dogs and cats femoral head and neck excision is frequently performed as a successful treatment for several hip diseases including Calvé-Legg-Perthes, femoral head and acetabular fractures, coxofemoral luxations and severe osteoarthritis (Piermattei and Flo 1997). In ponies with coxofemoral luxation femoral head resection is considered to cause a reduction in pain (Jogi and Norberg 1962, Platt et al. 1990, Malark et al. 1992) and this may be the main advantage over conservative treatment, which is generally considered to be unrewarding (Fessler and Amstutz 1974, Bennet et al. 1977). This is confirmed by our findings that weight bearing in the pony improved rapidly after surgery. The pain is caused by bone-on-bone movement of the femoral head against the dorsal acetabular ridge and ilium. Approximately one third of the femoral head had been eroded and there was extensive periosteal bone formation on the dorsal acetabular ridge and proximal femur.

Femoral head resection has been previously described with varying degrees of success in cases of coxofemoral luxation (Platt et al. 1990, Squire et al. 1991). The prognosis is largely dependent on patient weight. Squire et al. (1991) reported success in a pony yearling weighing less than $100 \mathrm{~kg}$, but failure in two ponies weighing more than $200 \mathrm{~kg}$. Platt et al. (1990) successfully operated a 5-year old pony weighing 150 $\mathrm{kg}$ with chronic coxofemoral luxation. The pony in this report weighed $67 \mathrm{~kg}$ and the relatively low bodyweight certainly contributed to the successful outcome. In heavy animals, even if reposition is successful, retention may be more susceptible to breakdown during recovery.

Osteotomy of the greater trochanter provides excellent exposure of the coxofemoral joint, allowing accurate assessment of the extent of the damage to the acetabulum and surrounding structures. Several techniques can be applied to reattach the trochanter. Squire et al. (1991), who performed this technique on experimental animals, used two or three $6.5 \mathrm{~mm}$ cancellous screws and Garcia-Lopez et al. (2001) used Steinmann pins and orthopedic wire to reattach the greater trochanter following transposition in a miniature horse with coxofemoral luxation. In the present case Steinmann pins and orthopedic wire were used. The osteotomy, and its reattachment, did not lead to clinical complications in any of the cases described.

Rupture of the peroneus tertius muscle in the contralateral limb was diagnosed by clinical examination. If coxofemoral luxation was the result of trauma it is possible that rupture of the peroneus tertius muscle occurred at the same time. Another possibility is that the rupture was the result of excessive weightbearing on the contralateral, healthy limb which would explain the increased swelling noticed over time by the owner. Normally this type of injury heals without problems when the horse or pony is confined to a box and the affected leg can be rested (Mcllwraith 1987). One week after surgery extreme extension of the left hind hoof was noticed and rupture of the deep digital flexor tendon was feared. However, no rupture could be palpated and deep palpation of the tendons did not elicit a pain response and tendon laxity was considered to be the cause of this clinical observation. The problem resolved after a shoe with extended branches was applied. Tendon laxity was considered to be the result of the extended period of abnormal weightbearing on the left limb and the inactivity of the pony. Both the peroneus tertius muscle rupture and the tendon laxity healed but they emphasize the importance of early diagnosis and treatment, enabling a return to normal weight-bearing and (a limited amount of) exercise.

It is concluded that in (small) ponies weighing less than 100$150 \mathrm{~kg}$, surgical intervention is feasable in cases of coxofemoral luxation. Surgery should be performed as soon as possible after the diagnosis has been confirmed as this may result in successful reposition and fixation. During surgery osteotomy of the greater trochanter provides excellent exposure of the joint allowing more accurate repositioning and fixation of the femoral head within the acetabulum. When luxation is chronic or there is too much damage to the acetabulum and/or femur, femoral head resection is a realistic alternative. Early recognition and treatment of coxofemoral luxation enhance the prognosis and prevent extended periods of nonweightbearing lameness which can lead to problems of the contralateral hindlimb.

\section{Literature}

Adams O. R. (1957): Preliminary report on repair of coxofemoral luxation and coxofemoral subluxation in cattle. J. Am. Vet. Med. Assoc. 131, 515-519

Bennet D., J. R. Campbell and J. R. Rawlinson (1977): Coxofemoral luxation complicated by upward fixation of the patella in the pony. Equine Vet. J. 9, 192-194

Clegg P. D. and R. J. Butson (1996): Treatment of a coxofemoral luxation secondary to upward fixation of the patella in a Shetland pony. Vet. Rec. 138, 134-137

Fessler J. F. and H. E. Amstutz (1974): In: Textbook of large animal surgery. Eds. F. W. Oehme and J. E. Prier, Williams and Wilkins, Baltimore, 324-326

Foerner J. J. (1992) In: Equine Surgery. Ed. J. A. Aver, W.B. Saunders, Philadelphia, 1055

Garcia-Lopez J. M., R. J. Boudrieau and P. J. Provost (2001): Surgical repair of coxofemoral luxation in a horse. J. Am. Vet. Med. Assoc. $219,1254-1258$

Hunt C. A. and W. B. Henry Jr. (1985): Transarticular pinning for repair of hip dislocation in the dog: a retrospective study of 40 cases. J. Am. Vet. Med. Assoc. 187, 828-833

Jogi P. and I. Norberg (1962): Malformation of the hip joint in a standardbred horse. Vet. Rec. 74, 421-422

Knowles A. T., J. O. Knowles and R. P. Knowles (1953): An operation to preserve the continuity of the hip joint. J. Am. Vet. Med. Assoc. $123,508-515$

Lawson D .D. (1965): Toggle fixation for recurrent dislocation of the hip in the dog. J. Small An. Pract. 6, 57-59 
Lubbe A. M. and F. J. M. Verstraete (1990): Fascia lata loop stabilisation of the coxofemoral joint in the dog and cat. J. Small An. Pract. 31, 234-238

Malark J.A., A.J.Nixon, M. A. Haughland and M. P. Brown (1992): Equine coxofemoral luxations: 17 cases (1975-1990). Cornell Vet. 82, 79-90

Mcllwraith C. W. (1987): In: Adams' Lameness in Horses. Ed. Stashak, T.S. Lea \& Febiger, Philadelphia, 471

Meij B. P., H. A. W. Hazewinkel and R. C. Nap (1992): Results of extra-articular stabilisation following open reduction of coxofemoral luxation in dogs and cats. J. Small An. Pract. 33, 320-326

Nyack B., M. J. Willard, J. Stott and C. L. Padmore (1982): Non-surgical repair of coxofemoral luxation in a quarter horse filly. Equine Pract 4, 11-14

Piermattei D.L. and G. L. Flo (1997): Femoral head and neck excsision. In: Brinker, Piermattei and Flo's Handbook of Small Animal Orthopedics and fracture repair. 3rd Ed W.B. Saunders, Philadelphia, 459-464

Platt D., I. M. Wright and J. E. Houlton (1990): Treatment of chronic coxofemoral luxation in a Shetland pony by excision arthroplasty of the femoral head: a case report. Br. Vet. J. 146, 374-379
Spiers V. C. and R. Wrigley (1979): A case of bilateral hip dysplasia in a foal. Equine Vet. J. 11, 202-204

Squire K.R., J. F. Fessler, J. P. Toombs, D. C. Van Sickle and W. E. Blevins (1991): Femoral head ostectomy in horses and cattle. Vet. Surg. 20, 453-458

Stashak T. S. (1987): In: Adams' Lameness in horses. Ed. Stashak, T.S. Lea Febiger, Philadelphia, 748-749

Zakiewicz M. (1967): Recurrent hip luxation in the dog: skin as substitute ligament. Vet. Rec. 81, 538-539

R. van den Boom, DVM

Department of Equine Sciences

Faculty of Veterinary Medicine

Utrecht University

Yalelaan 12

NL 3584 CM Utrecht

e-mail:R.vandenBoom@vet.uu.nl 